\title{
PELAYANAN PUBLIK DAN KEADILAN SOSIAL
}

\author{
Khoiron \\ Departemen Administrasi Negara/Publik Universitas Islam Malang \\ Email; khoiron@unisma.ac.id
}

\begin{abstract}
In the life of nation and state, society or people should be treated equally in various fields of life because the state is the result of social cooperation between people with each other, or among the children of the nation. In this case, the state is the government (umaro '), is the institution who most responsible for the basic services of its people. In the Islamic perspective, there is no clear system of governance, whether the governance is democratic or other systems. Islam only teaches how the country is managed with a trusteeship leader over his power. The value of ethics (morals), or morality, and justice and others is a guidebook as a trustful leader. Public service is the most fundamental basic need for citizens. Thus, the state must grant such this right to entire people without any discrimination and even provide an excellent service to the most disadvantaged communities in their social life. One of the great attitudes of the leader in Islamic scholar is Al-adalah or justice. Justice is so easy to pronounce, but it is difficult to achieve in every public policy. In qo'idah fiqihyah it is explained that "tasarruful imam ala al-roiyati, manutun bil almaslahah", (the policy of a leader must base on the principle of greater utility to all his society). Thus, any policy in this regard is public service, issued by the state or government should consider the broadest utility principle (utilitarianism). Therefore, this paper will discuss about the social justice service from a normative-prescriptive perspective but also in the perspective of Islam as a religion of liberation. Islam is a religion of liberation from oppression, ignorance and complete religion.
\end{abstract}

Key word: Public Services and Social Justice.

\section{PENDAHULUAN}

Sudah lazim bahwa pelayanan publik (public services), adalah tugas utama birokrasi pemeritahan suatu Negara. Sebagai lembaga publik, birokrasi pemerintahan secara konstitusional dan moral berkewajiban melayani kebutuhan setiap warga masyarakatnya, jauh menanggalkan sikap dan praktik-praktik diskriminasi antar suku, golongan, agama dan lain lain sebagainya. Namun, memang kita harus jujur pada diri kita semua bahwa selama rezim orde baru berkuasa, birokrasi publik seolah-olah menampilkan wajah yang dingin, tidak santun, boros, dan penuh jebakan administrasi dan kekuasaan. Birokrasi pada zaman itu layakanya hutan belantara, setiap saat ada binatang buas yang siap menerkam siapa saja pendatang. Sehingga tidak berlebihan jika masyarakat awam terkadang tidak berani menghadapi sosok yang menjadi pengayomnya sendiri. Sungguh ironis, dan menyedihkan jika mendengar cerita-cerita masyarakat selama orde baru berkuasa dalam melayani publik.

Fenomena mal-administrasi, pungutan liar, uang suap, hingga nepotisme dan penyelahgunaan kewenangan (abuse of power) seakan menjadi penyakit birokrasi yang tidak berkesudahan. Hal itu tentu menunjukkan bahwa patologi birokrasi masih menjadi perkerjaan berat para pemimpin bangsa ini. Birokrasi yang adil, yang melayani sepenuh hati kepada seluruh warga negara bukan sebuah dongeng, namun fakta yang terus menerus menjadi budaya birokrasi kita. Namun, saya masih mempunyai optimisme 
bahwa birokrasi kita pada akhirnya akan menuju birokrasi yang dekat dengan rakyat, dan melayani dengan prima sepanjang political will pejabat negara mempunyai sikap yang jujur dan amanah.

Sebagai Negara berkembang, Indonesia harus berlari mengejar ketertinggalaannya dengan negara-negara lain di dalam membenahi dan mereformasi kelembagaan dan sektor. Sebagaimana yang sudah kita ketahu bahwa sejak dilantik sebgai presiden RI, Bapak Joko Widodo berkomitmen merubah mental birokrasi yang lebih bersifat "pangreh praja" menuju birokrasi yang "melayani" semua rakyat, masyarakat Indonesia. Revolusi mental yang dikampayekan oleh bapak Presiden kepada segenap elemen bangsa, menjadi obat, jamu dan sekaligus solusi atas problem sosial, politik, ekonomi, hukum dan kebudayaan bangsa. Sebagai gambaran saja, dalam bidang kehidupan sosial, Presiden menekankan agar setiap warga bangsa bahu-membahu secara gotong-royong memecahkan problem yang muncul di tengah-tengah masyarakat. Dalam kehidupan politik, presiden memberikan suri tauladan kepada para pembantunya, para gubernurnya hingga pejabat yang paling rendah di seluruh nusantara, bahwa sebagai pejabat publik, abdi masyarakat tidak harus mempertontonkan kehidupan pribadi yang mewah dan serba mahal.

Di dalam kehidupan ekonomi sebagai pilar kesejahteraan masyarakat, untuk menarik investor baik dalam dan luar negeri presiden mengeluarkan beberapa paket kebijakan ekonomi yang intinya agar pelayanan publik (public services), lebih cepat, mudah, murah dan berkualitas. Sebab, sektor ekonomilah ukuran kemajuan sebuah Negara. Sehingga, sektor ini benar-benar digarap dengan serius oleh pemerintah pusat.

Pada sektor hukum, pemerintah berusaha menampilkan wajah para mengayom masyarakat menjadi mitra terbaik rakyat dalam rangka mengamankan tindakan yang melanggar hokum yang berlaku. Aparat keamanan diharapkan mampu berbuat secara adil dan profesional dalam menjaga ketertiban umum. Prinsip hukum adalah semua orang sama di hadapan hukum "equality before the law", sehingga tidak ada lagi hukum tumpul ke-atas dan tajam ke-bawah. Sedangkan dalam kehidupan budaya, persiden mengajak untuk hidup yang penuh dengan prinsipprinsip moral dan etika dalam pergaulan. Baik dalam kehidupan keluarga, bermasyarakat berbangsa dan bernegara.

Kebijakan otonomi dan desentralisasi harus dapat diimplementasikan dengan benar dan sesuai dengan target-target pembangunan baik daerah dan nasional. Oleh karena itu, sebagai daerah otonom, pemerintah daerah harus berkerja secara kreatif, inovatif dan berkelanjutan (sustainable), dalam merubah mental aparatur Negara dari sikap yang apatis terhadap perubahan sosial. Sebagai bagian dari masyarakat modern, kita semua tentu berharap agar penyelenggaraan pemerintahan terutama pemerintahan daerah wajah birokrasinya dijauhkan dari kesan seram, dan menakutkan bagi masyarakat. Sebab, diakui atau tidak masyarakat kita sudah terlanjur "trauma" terhadap wajah birokrasi selama rezim otoriter pemerintahan pusat hingga berdampak kepada wajah birokrasi di daerah.

Sehingga, pada zaman modern ini pelayanan publik harus mampu memenuhi 
keinginan masyarakat modern yang menuntut hak di dalam mendpatkan pelayanan dasar yang sesuai dengan nilai-nilai, norma dan tuntunan agama. Sebagai negara yang berpenduduk muslim terbesar, seharusnya potret pelayanan yang berkeadilan harus menjadi dasar disetiap layanan publik. Layanan kesehatan, pendidikan dan lain sebagainya yang menjadi tuntutan masyarakat harus menjadi tujuan utama di dalam membangun budaya pemerintah yang bernafaskan keadilan sosial.

\section{KAJIAN PUSTAKA}

\section{Pelayanan Publik (Public Services)}

Kemajuan sebuah bangsa dan Negara biasanya di lihat sejauhmana pembangunan nasionalnya. Pembangunan nasioanal tentu membutuhkan dukungan dari para steksholders dan elemen masyarakat yang lain. Bahkan dalam urusan ekonomi, pelayanan menjadi kebutuhan fundamental dalam memberikan peluang kepada investor di dalam menanamkan sahamnya Sehingga, tidak salah jika kemudian dunia global menuntut perbaikan pelayanan publik melalui konsep "good government" hingga "good governance" untuk yang terakhir bermakna tata kelola pemerintahan yang baik.

Menurut Kotler, bahwa pelayanan adalah setiap kegiatan yang menguntungkan dalam suatu kumpulan atau kesatuan, dan menawarkan kepuasan meskipun hasilnya tidak terkait pada suatu produk secara fisik (Sampara Lukman; 2000). Produk adalah alat untuk praktik bertransaksi di dalam pelayanan publik, sehingga terkadang masyarakat tidak mementingkan produknya, namun sebaliknya masyarakat cenderung melihat dari aspek kualitas pelayanan yang diberikan oleh sebuah instansi. Misalnya, jika kita melihat penjual rokok produk lokal akan tetapi yang menjualkan itu adalah sekelompok wanita SPG (sale promotion girl), yang sangat ramah dan santun, maka kebanyakan masyarakat akan merasa senang dan membelinya meski harganya terkadang jauh lebih mahal. Tetapi, kepuasan di dalam mendapatkan pelayanan yang super prima itulah yang menjadi dimensinya yaitu pelayanan prima.

Pelayanan prima atau "excellence service" adalah suatu sikap atau cara karyawan dalam melayani pelanggan dengan memuaskan. Pelayanan prima merupakan suatu pelayanan terbaik, melampaui, melebihi, mengungguli pelayanan yang diberikan pihak lain atau daripada pelayanan waktu yang lalu (Tim diklat. BPPK.2008).

Masyarakat sebagai objek pelayanan harus di tempatkan secara proporsional, artinya bahwa penyedia layanan jasa harus memaksimalkan potensi dan sumber daya yang dimilikinya untuk terfokus pada bagaimana memberikan layanan yang berkualitas. Sistem pemberian pelayanan yang baik dapat dilihat dari besarnya sumber daya manusia yang dimiliki oleh birokrasi secara efektif didayagunakan untuk melayani kepentingan pengguna jasa (Agus Swiyanto dkk. 2006). Sehingga, pelayanan publik benarbenar lebih merata dan jauh dari tindakan diskriminatif terhadap masyarakat kelas bawah. Sebagai contoh, dalam pelayanan kesehatan, di Indonesia memang sudah terdapat berbagai program jaminan kesehatan ASKES, BPJS dan lain lain, akan tetapi fenomena masyarakat yang ditolak di rumah 
sakit, ditahan akibat belum mampu membayar biaya, dan lain sebagainaya adalah contoh yang paling baik bahwa pelayanan publik oleh aparatur negara masih bersifat diskriminatif dan jauh dari nilai-nilai keadilan. Kekayaan alam yang melimpah dikelola dengan benar oleh pemerintah, baik pemerintah pusat maupun daerah. Sebab, tanpa pengelolaan yang baik kesejahteraan masyarakat lokal dan nasional menjadi taruhannya (Khoiron. 2017; 241).

\section{Prinsip Pelayanan dan Good Governance}

Pembangunan di negara-negara maju, konsep good governance sebagai dasar dari bagaimana pemerintahan dilaksanakan pelayanan berdasarkan prinsip-prinsip akuntabilitas, rule of law, keadilan, transparansi dan prinsip-prinsip yang lain demi menjaga amanah. Konsep good governance sendiri lahir sekitar tahun 1980an, yang dimotori oleh World Bank dengan penjelasan tentang "governance and development", seputar implementasi dari prinsip-prinsip akuntabilitas, transparansi dan rule of law.

Di indonesia, konsep good governance atau tatakelola pemerintahan yang baik muncul ketika krisis ekonomi melanda sejak tahun 1997 silam, yang kemudian menumbangkan rezim orde baru. Bahwa salah satu di antara penyebab ekonomi indonesia terguncang akibat guncangan ekonomi dunia terutara kawasan Asia, adalah buruknya pengelolaan dan manajemen di sektor publik. Banyak kasus korupsi, kolusi da nepotisme mengakibatkan rotasi kekuasaan dan pendistribusian hasil kekeyaan negara tidak seimbang. Bahkan, kekuasaan cenderung mengkooptasi stekhorders yang lain, pahadal membangun bangsa harus ada kerjasama sosial yang jujur, dan bertanggungjawab di antara stekholders.

Konsep good governance di era desentralisasi dan otonomi daerah menjadikan daerah harus mampu memanfaatkan kebijakan tersebut. Daerah diberikan kebebasan untuk membangun daerah atau wilayahnya sesuai dengan prakarsa dan kebutuhan daerah berbasiskan pada kearifan, dan budaya setempat. Pelayanan publik yang mudah, murah dan berkualitas adalah jawaban dari pada pemerintah daerah yang telah diberi kewenangan oleh pemerintah pusat.

Dalam konteks tata kelola pemerintahan yang baik (good governance), kita mengenal beberapa pilar yang mendasarinya, yakni adanya negara (state), swasta (private state), dan masyarakat madani (civil society). Ketiga pilar tersebut harus sedapat mungkin bekerja secara benar dan penuh dengan tanggung jawab.

Sebagai contoh, negara (state), berkewajiban memberikan kebijakan (policy) yang mengarah kepada kemudahan bagi setiap orang untuk berinvestasi atau menanamkan modalnya di seluruh wilayah negera, sepanjang tidak menciderai rasa keadilan sosial. Sehingga, negara mendapatkan bantuan dalam pembangunan negara secara nasional.

\section{KEADILAN SOSIAL DALAM LAYANAN PUBLIK}

Pemaknaan keadilan (justice), secara sederhana yaitu memberikan sesuatu sesuai dengan porsinya masing-masing, atau 
memperlakukan hal yang sama kepada sesuatu yang sama dan sebaliknya, memperlakukan hal yang berbeda kepada sesuatu yang berbeda. Maka, jika kita analogikan pemberian uang saku secara nominal kepada anak SD dan SMP. Pengertian sederhana itu sudah sangat mafhum bagi kita semua yang biasa dan sedang mempunyai anak sekolah. Kenapa berbeda nilai nominalnya, tentu berbeda kebutuhan antara anak sekolah dasar (SD), dan sekolah menengan pertama (SMP). Tetapi tidak jarang anak orang kaya yang masih SD bisa mendapatkan uang saku yang jauh lebh besar dari anak sekolah SMP dari keluarga yang kuran mampu. Tentu contoh ini belum menjawab pertanyaan soal keadilan.

Menurut John Rawl seorang ilmuan abad ke-20 dalam buku "A theory of justice" menjelaskan bahwa keadilan adalah sebuah "fairness" (Jhon Rawls; 1995). Kata "fairness", dapat diterjemahkan secara filosifis bahwa keadilan harus memberikan kesempatan yang sama kepada seluruh warganya, atau setiap individu mempunyai posisi yang sama , setara dalam potensi dan kesempatan. Bagi John Rawls, terdapat dua prinsip keadilan yang sedapat mungkin dimiliki oleh setiap level pemimpin disuatu negara yakni Pertama, setiap orang mempunyai hak yang sama atas kebebasan dasar yang paling luas, seluas kebebasan yang sama bagi semua orang. Kedua, ketimpangan sosial dan ekonomi mesti diatur sedemikian rupa sehingga, (a) dapat diharapkan memberikan keuntungan semua orang, terutama bagi mereka yang paling kurang beruntung dan (b) semua posisi dan jabatan terbuka bagi semua orang (John Rawls; 1995).
Pelayanan harus menyentuh masyarakat yang paling kurang beruntung di dalam sistem sosialnya. Misalnya, pembangunan daerah tertinggal harus di utamakan dan diberikan askes yang lebih luas dan besar. Adalah sebuah keadilan jika pembangunan jalan trans-papua dapat dilakukan oleh negara. Sebab, rakyat papua sudah lama menderita sejak merdeka papua salalu terteintkakakl adie pmbangunan dari wilayah lain. Namun, itu adalah contoh bagaimana pembangunan yang berkeadilan di wilayah Indonesia. Contoh lain, bahwa kenaikan bahan bakar minyak adalah penjelasan yang paling baik mengenai prinsip keadilan yang pertama, yakni dimana orang kaya tidak diperkenankan membeli BBM bersubsidi, hanya masyarakat level bawahlah yang berhak mendapatkannya. Pemerintahan yang adil dan baik adaalah dengan kebijakankebijakan yang pro-rakyat terutama masyarakat miskin.

Bagi Morris Ginsberg, ketidakadilan muncul pada saat hal yang sama diperlakukan secara tidak sama, dan juga ketika hal yang tidak sama diperlukan sama (Morrins Ginsberg; 2003). Sehinnga, dalam kontek pembangunan ekonomi bangsa, setiap warga seharusnya mempunyai hak yang sama dalam mengakses pelayanan publik yang berkualitas. Pemerintah, sebagai penyedia layanan publik tidak diperkanankan berperilaku diskriminatif terhadap masyarakat kelas bawah. Semua kelas di dalam masyarakat harus diperlakukan sama di depan pelayanan publik, lebih-lebih pada pelayanan hukum dan keamanan.

\section{Keadilan dalam Perspektif Teologis Islam}


Islam adalah agama paripurna, di dalamnya mengandung ajaran untuk menuju kehidupan yang sejahtera. Islam adalah agama pembebasan dari persoalan kehidupan manusia. Dalam surat al-nahl ayat 90 yang artinya, sesungguhnya Alloh SWT menyuruh (kamu) berlaku adil dan berbuat kebajikan, memberi bantuan kepada kerabat, dan melarang (melakukan) perbuatan keji, kemungkaran dan permusuhan. Dia memberi pelajaran kepadamu agar kamu dapat mengambil pelajaran. Ayat tersebut merupakan perintah tuhan kepada setiap level pemimpin, untuk berbuat adil dan kebajikan. Berperilaku adil dalam menjalan amanah rakyat, tentu merupakan akhlaq yang baik untuk kemudian mampu mengelola negara dengan prinsip-prinsip akhlaq dan moralitas yang tinggi.

Dalam kehidupan yunani yang bersifat homogen, keadilan merupakan keutamaan berpolitik agar warga bisa hidup sesuai dengan posisi dan kodratnya masing-masing, maka pada kehidupan sosial modern yang heterogen, keadilan adalah prinsip rasional yang mengendalikan tindakan-tindakan politik untuk menjamin kesatuan, kestabilan, dan kelanggengan masyarakat (Bur Rasuanto; 2005).

Pengertian adil menurut Yatimin Abdullah, (akhlak; 1998), bahwa keadilan adalah menempatkan sesuatu sesuai dengan proporsinya, dan persamaan hak sesuai dengan kapasitas dan kemampuan seseorang dalam melakukan suatu pekerjaan. Keadilan juga berarti keseimbangan antara berat dan muatan, sesuai antara hak dan kewajiban, sesuai antara pekerjaan dan hasil yang diperoleh, sesuai dangan ilmu, sesuai dengan pendapatan dan kebutuhan. Sehingga, konsep keadilan sangat erat dengan persoalan hak dan kewajiban seseorang. Jika seseorang telah melaksanakan kewajibannya dengan baik dan benar, adalah hak dia untuk mendapatkan sesuatu yang menjadi hak pribadinya. Pemberian hak atas kewajiban yang telah dilakukan oleh masyarakat itu kemudian menjadi kewajiban pemimpin atau pemerintah. Jika masyarakat telah membayar pajak, tentu tidak boleh lagi ada jalan, jembatan dan insfrasuktur yang lain rusak yang dapat melanggar hak untuk mendapatkannya. Jika seoarang mahasiswa telah melakukan pembayaran uang kuliah dan pembayaran yang lain, tidak boleh lagi ada dikelas yang tidak ber-AC, perpustakan yang memadani, gazebo-gazebo yang representative, dan hak-hak lain yang melekat atas pembayaran biaya perkuliahan tersebut (Khoiron. 2017; 241).

Di dalam perspektif islam, keadilan bermakna cara dalam mengatur semua segi kehidupan manusia secara seimbang dan menyeluruh (yatim abdullah; 1995). Sehingga, pembangunan daerah tertinggal oleh negara merupakan kewajiban konstitusi, lebih jauh lagi maka hal itu menjadi kewajiban pemimpin jika ditinjau dari aspek agama. Karena keadilan adalah sebuah cara, metode di dalam mengelola negara, pemimpin harus bekerja dengan sungguh-sungguh di dalam menggunakan cara menuju kesejahteraan rakyat.

Dalam Islam, tidak mengenalkan sistem kelas di dalam sistem sosial-masyarakat. Sebab, bagi islam orang yang paling mulia adalah manusia yang paling baik taqwanya. Sebagaimana firman Alloh SWT dalam surat 
yang artinya, sesungguhnya orang yang paling mulia di hadapan Alloh adalah orang yang paling baik ketaqwaannya. Manusia yang bertaqwa di dalam kehidupan pemerintahan bahwa birokrasi berkewajiban secara relegius untuk memberikan yang terbaik kepada umat. Birokrasi yang di isi dengan orang-orang yang bertaqwa akan lebih demokratis, ramah, santun dan berkualitas. Sebab, dengan perilaku demikian menjadi gambaran atau manifestasi dari pernyataan diri sebagai khalifah atau wakil tuhan di Bumi. Birokrasi yang takut kepada Tuhan akan membawa dampak yang sangat nyata bagi masyarakatnya. Namun, sebaliknya birokrasi yang korup, dan sewenang-wenang akan menanggung dosa kepada seluruh rakyatnya.

Islam mengajarkan kepada umat manusia, untuk selalu dapat berbuat adil sebagaimana khotbah jumat yang selalu di sampaikan oleh para khotib di masjid-masjid. Oleh karena itu, berbuat adil adalah sebuah kewajiban bagi umat manusia yang mengaku beriman dan bertaqwa kepada Tuhan YME, sesuai dengan derajat kemampuannya di dalam memahami persoalan keadilan itu sendiri.

\section{KESIMPULAN}

Bahwa, keadilan dan ketidakadilan itu hadir disetiap interaksi sosial-masyarakat di dalam kehidupan individu, berbangsa dan bernegara. Tentu keadilan yang paripurna hanya milik tuhan YME, sebagai khalifah atau wakil dari tuhan di bumi, manusia dituntut untuk berperilaku mendekati keadilan. Indonesia memang bukanlah negara agama, akan tetapi sebagai negara yang mengakui agama, sudah sepantasnya nilai-nilai keadilan harus dapat diimplemetasikan di setiap bidang kehidupan masyarakat. Birokrasi pemerintah adalah lembaga yang paling bertanggung jawab atas terselenggaranya nilai-nilai keadilan sosial di masyarakat.

\section{DAFTAR PUSTAKA}

Abdullah, Yatimin. (2007). Studi Akhlak Dalam Perspektif Al-Qur'an. Jakarta: PT. AMZAH

Dwiyanto, Agus. (2006). Good Governance dalam Pelayanan Publik, Yogyakarta; Gama Press Ginsberg, Morris. (2003). On Justice in Society. Yogyakarta: Pustaka Jogja Mandiri. Bantul

Ginsberg, Morris. (2003). On Justice in Society. Yogyakarta: Pustaka Jogja Mandiri. Bantul

Khoiron. (2017). Membangun Pemerintah yang Berkeadilan Sosial. Ilmu Humaniora Sebuah Ontologi Pemikiran. Tangerang: PT. Nirmana Media

Lukman, Sampara. (2000). Manajemen Kualitas Pelayanan. Jakarta: LAN Republik Indoensia

Rawls, John. (2011). A Theory of Justice. Yogyakarta: Pustaka Pelajar; Indonesia

Rasuanto, Bur. (2005). Keadilan Sosial; Pandangan Deontologis Rawls dan Habermas, Dua Teori Filsafat Politik Modern. Jakarta: PT. Gramedia Pustaka Utama

Tim Pusdiklat Pegawai. (2008). Pelayanan Prima. Jakarta: Badan Pendidikan dan Pelatihan Keuangan Press. 